\title{
A CRÍTICA DE KANT A HobBES EM TEORIA E PRÁTICA
}

Aguinaldo Pavão

Universidade Estadual de Londrina (Paraná)

Pretendo nesse artigo verificar se a crítica de Kant a Hobbes na segunda parte de Teoria e Prática (TP) faz jus à compreensão hobbesiana acerca da relação entre indivíduo e autoridade política ${ }^{1}$. Para tanto, dividirei minha exposição em três partes. 1) Inicialmente apresentarei de forma genérica a compreensão kantiana sobre o poder político. 2) Em seguida, farei breves considerações comparativas entre Kant e Hobbes. 3) Por fim, irei me deter na passagem de TP (A 264) em que Hobbes é explicitamente visado por Kant.

Em resumo, a idéia que apresentarei é a seguinte: segundo Kant, a tese de Hobbes de que o soberano nunca age injustamente estaria errada porque Hobbes teria deixado de notar que injustiça deve ser entendida como um reconhecimento do direito de coação (Zwangsrecht) ao lesado. Portanto, o erro de Hobbes teria sido o de não ter restringido o conceito de injustiça, mas o tomado na sua generalidade. Para Kant, tal tese é terrível (erschrecklich) (TP A264). Quero, porém, defender que a distinção hobbesiana entre injustiça e iniqüidade permite que se pense numa restrição ao conceito de injustiça ou injúria. Defenderei, pois, que é possível pelo menos enfraquecer o alcance da crítica de Kant a Hobbes. Se estiver certo, será lícito afirmar que Hobbes tem muito mais a dizer sobre a relação entre súdito e soberano do que pensou Kant. Entendo que, para

\footnotetext{
${ }^{1}$ Uso as seguintes abreviaturas: a) Textos de Kant: TP: "Sobre a expressão corrente: isto pode ser correcto na teoria, mas nada vale na prática"; DD: Doutrina do Direito; R: A Religião nos Limites da Simples Razão; PP: À paz perpétua; LE: Lecciones de Ética; Collins: "Moralphilosophie Collins"; FMC: Fundamentação da Metafisica dos Costumes; Ilum.: Resposta à pergunta: que é o iluminismo?; CF: $O$ Conflito das Faculdades. b) Textos de Hobbes: EDNP: Elementos do Direito Natural e Político; DC: De Cive; L: Leviatã e DFJ: Diálogo entre um Filósofo e um Jurista.
}

Philosophica, 31, Lisboa, 2008, pp. 91-101 
Hobbes, do fato de súdito reconhecer que todas as ações do soberano são justas não se segue que ele julgue que todas as ações do soberano sejam irrepreensíveis.

O procedimento de justificação do poder político em Kant é similar ao da tradição contratualista. É preciso, contudo, ter muito cuidado neste ponto. Ainda que Kant se sirva da terminologia contratualista (estado de natureza, contrato, estado civil), o seu pensamento prático torna esses conceitos carregados de uma semântica diversa daquela que se pode perceber em Hobbes e Locke. Para Kant, os conceitos de estado de natureza e contrato desprendem-se completamente de referências empíricas, portanto, também de móbiles fundados em cálculos de interesse. Não é a proteção à vida, liberdade e bens, como em Locke, mas o dever que a razão determina, o fundamento para ingressarmos numa comunidade política.

Kant avalia que no estado de natureza (no qual ele inclui o direito privado) os homens vivem numa situação cuja estabilidade é permanentemente provisória, devido à falta do estado civil que, mediante leis, estabeleça e garanta o meu e o teu, bem como o exercício da liberdade. Convém registrar que Kant distingue estado social de estado civil (cf. $D D, \S$ 41, Ak 306). O estado social pode ter lugar no estado de natureza, mas, como tal, sempre exposto à dissolução se alguém abusar do que é o direito privado do outro. Por certo, a razão reconhece a vulnerabilidade dos direitos neste estado, mas o mais importante é que ela postula como um ideal seu o estado civil, estabelecendo o dever de sairmos do estado de natureza e ingressarmos, por um contrato, no estado civil, onde tem validade (garantia), pelo direito público, o direito privado. Mas, advirta-se, a expressão "por um contrato" não quer dizer que os indivíduos irão realizar empiricamente um pacto. A razão não precisa de quaisquer espécies de certificações históricas para a determinação de suas leis.

Desse modo, para Kant, a saída do estado de natureza e o ingresso no estado civil não dependem de ponderações prudenciais que poderiam gestar um imperativo hipotético tal como: se queres viver em paz, ingressa no estado civil. A entrada no estado civil é imperativamente categórica. Diz Kant:

... a primeira coisa que o homem se vê obrigado a decidir, se não quer renunciar a todos os conceitos jurídicos, é o princípio: é mister sair do estado de natureza, no qual cada um age conforme ao seu capricho, e unir-se com todos os demais (com os quais não pode evitar entrar em interação) para submeter-se a uma coação externa legalmente pública; portanto, entrar em um estado em que a cada um se lhe determine le- 
galmente e se lhe atribua desde um poder suficiente (que não seja o seu, mas um exterior) o que deve ser reconhecido como seu; isto é, que deve entrar antes de tudo em um estado civil ( $D D, \S 44$, Ak 312).

No § 49 da DD [Ak 318], Kant sustenta que o Estado Constitucional (com divisão de poderes, mantido segundo leis da liberdade) é uma aspiração que a razão nos impõe "através de um imperativo categórico".

Mas o que entende Kant por Estado? Para Kant o Estado (civitas) é "a união de um conjunto de homens sob leis jurídicas" $(D D, \S 45, \mathrm{Ak}$ 313). E o "estado civil, considerado simplesmente como situação jurídica, funda-se nos seguintes princípios a priori: 1 . A liberdade de cada membro da sociedade, como homem; 2. A igualdade deste com todos os outros, como súdito; 3 . A independência de cada membro de uma comunidade, como cidadão" (TP A 235).

A liberdade como princípio a priori da constituição de um Estado se exprime na fórmula:

Ninguém pode me constranger a ser feliz à sua maneira (como ele concebe o bem estar dos outros homens), mas a cada um é permitido buscar sua felicidade pela via que lhe parecer boa, contanto que não cause dano à liberdade dos outros (isto é, ao direito de outrem) aspirarem a um fim semelhante, e que pode coexistir com a liberdade de cada um, segundo uma lei universal possível (TP A 235-236).

O segundo princípio a priori do estado civil é a igualdade, "cuja fórmula se pode estabelecer assim: cada membro da comunidade possui um direito de coação sobre os outros, excetuando apenas o chefe de Estado (porque ele não é membro desse corpo, mas o seu criador ou conservador), o qual é o único que tem o poder de constranger, sem ele próprio estar sujeito a uma lei coerciva" (TP A 233-234). Por fim, o estado civil funda-se na independência (sibisufficientia), princípio a priori que se refere ao "membro da comunidade como cidadão, isto é, como colegislador" (TP A 244).

\section{II}

Eu afirmei antes que o conceito de estado de natureza em Kant se distingue do de Hobbes, porquanto ele não se reporta a elementos empíricos, vale dizer a móbiles fundados em cálculos de interesse. Isso poderia dar a entender que sobre o estado de natureza Kant e Hobbes estão em desacordo profundo. Não se pretende, contudo, passar essa mensagem. $\mathrm{Na}$ verdade, não é despropositado pensar que Kant sustenta uma tese sobre o estado de natureza de viés aparentemente hobbesiano. Em várias 
passagens de sua obra ${ }^{2}$ encontramos referência à idéia de um estado de natureza como um "estado em constante disposição de guerra" (R: 40/B 29-30). Ainda na Religião Kant declara que o estado de natureza

é um estado em que cada qual quer ele próprio ser juiz sobre o que é o seu direito frente a outros, mas não tem por parte dos outros nenhuma segurança, a não ser cada um a sua própria força; é um estado de guerra em que todos devem constantemente estar armados contra todos $(\mathrm{R}$ : 103n/B 136n).

Em À Paz Perpétua Kant escreve, revelando uma proximidade notável com Hobbes, que o estado de natureza representa uma "ameaça permanente" de hostilidades, ainda que nem sempre ocorra a eclosão destas (cf. PP Ak 349). Parece-me patente, portanto, a inclinação hobbesiana da compreensão de Kant do estado de natureza. De fato, Hobbes ponderou que "sem um superior comum na terra" que garanta a paz, os homens viverão num estado de guerra. Este estado de guerra, Hobbes esclarece, não significa o conflito empírico, mas a disposição para tal enquanto não existe outra garantia de segurança, exceto a força e a astúcia que cada um pode empregar por conta própria em seu benefício.

[...] durante o tempo em que os homens vivem sem um poder capaz de os manter a todos em respeito, eles se encontram naquela condição que se chama guerra; e uma guerra de todos os homens contra todos os homens. Pois a guerra não consiste apenas na batalha, ou no ato de lutar, mas naquele lapso de tempo durante o qual a vontade de travar batalha é suficientemente conhecida (L XIII 8: 109)³.

Sendo assim, talvez não seja uma precipitação levantar a hipótese de que a divergência mais saliente de Kant com relação a Hobbes esteja na rejeição kantiana do contratualismo do autor do Leviatã, pois é justamente daí que resulta o seu absolutismo. Com efeito, a formulação hobbesiana do contrato estabelece a necessidade de uma concessão total da força e

\footnotetext{
${ }^{2}$ Kant se refere ao estado de natureza na $C R P$ B 780, citando Hobbes: O estado de natureza seria um estado de injustiça e violência. Mas, em Hobbes, se levarmos em conta a sua declaração segundo a qual "onde não há poder não há lei [positiva], e onde não há lei não há injustiça” ( $L$ XIII $\S 13$, p. 111), o estado de natureza não seria um estado de injustiça. Todavia, Kant se corrige deste erro (cf. Terra 1995: 33) na $D D \S 44, A k$ 312. Aí ele distingue entre injustiça (Ungerechtigkeit) e ausência de justiça (Rechtlosigkeit). O fato de os homens guerrearem efetivamente não constitui injustiça no estado de natureza.

${ }^{3}$ Nesse sentido, parece proceder a afirmação de Oliveira de acordo com a qual "na segunda parte do Gemeinspruch Kant se propõe a ratificar a teoria hobbesiana do estado de natureza, reformular sua concepção de contratualismo e refutar o seu absolutismo" (Oliveira: 2002: 64).
} 
do poder dos contratantes ao soberano (seja a um homem, seja a uma assembléia) a fim de que o poder comum possa ser instituído. Assim, a diversidade volitiva é reduzida a uma só volição, pois Hobbes acredita que essa é a única maneira de se garantir uma estrutura coercitiva garantidora da paz. Por certo, isso vai muito além de um simples consentimento ou concórdia. A redução das diversas vontades a uma só - que envolve rigorosamente uma "submissão das vontades" (DC VI: § 3, 103) - significa o reconhecimento de que a designação de um homem ou uma assembléia de homens torna-os representantes das pessoas dos contratantes. Logo, os atos praticados pelo representante no tocante à paz e à segurança também deverão ser considerados atos daqueles que delegaram o poder. Com isso se chega a uma verdadeira unidade de todas as pessoas numa só e mesma pessoa, de tal forma que caberia a seguinte declaração dirigida de um homem para outro: "cedo e transfiro meu direito de governar-me a mim mesmo a este homem, ou a esta assembléia de homens, com a condição de transferires a ele teu direito, autorizando de maneira semelhante todas as suas ações" (L XVII: 105). Dessa forma, a multidão, unindo-se numa só pessoa, constitui o que propriamente deve ser chamado Estado.

Sendo o pacto realizado apenas entre cada um dos indivíduos e não entre eles de um lado e o soberano de outro, o soberano jamais pode violar qualquer preceito contratual. Pensar o contrário seria dotar de razoabilidade o irrazoável, isto é, supor um pacto obrigando o soberano dentro de certos limites, sendo que é precisamente o soberano que inaugura laços de obrigação contratual. Ele não pode estar sujeito a qualquer obrigação contratual, pois, para isso, deveria existir antes uma força para obrigá-lo a obedecer a estas regras.

Segundo Kant, o Estado obriga os seus membros incondicionalmente. Para Kant é sem sentido julgar que o súdito tem o direito de se opor às decisões do chefe de Estado. Uma das razões é a publicidade requerida como critério de justiça de uma ação. A exigência de publicidade, segundo Kant, não pode ser satisfeita, por quem quer se rebelar (cf. PP: Ak 381-383). A outra razão é a que, aparentemente, aproxima Kant de Hobbes. Esta se assenta na necessidade de se conceber um árbitro para julgar se o súdito ou o soberano está com a razão quando de um conflito. Mas tal juiz teria de ser um terceiro, para não haver julgamento em causa própria. Ora, [diz Kant] "seria, pois, preciso haver ainda um chefe que decidisse entre este e o povo - o que é contraditório" (TP: A 255). Assim, é preciso que quem decida seja o chefe de Estado, a ninguém cabendo o direito de lhe contestar a posse da administração da justiça (cf. TP: A $255)^{4}$.

${ }^{4}$ Veja também: DD, § 49, observação geral A. Sobre a negação do direito de resistência, veja ainda: CF, 2a. Parte, §6, n. (p. 104 ed. 70). 
Kant, embora negasse qualquer direito de resistência, procurou mostrar que o uso público (öffentliche Gebrauch) da razão (cf. Ilum. A 483 e ss), isto é, o exercício livre da crítica, não resultava num dissenso desagregador da sociedade política. O homem, como parte do mecanismo social, tem seus deveres e é obrigado a fazer uso privado (Privatgebrauch) da razão (obediência). Porém, ao usar publicamente a sua razão, ele se considera também como membro de uma comunidade total, e até da sociedade civil mundial (cf. Ilum. A 485). O considerar-se como um cidadão do mundo não implica danos à estabilidade da ordem política. Ao contrário, Kant pensa que a liberdade de escrever dos súditos será útil ao próprio soberano, que poderá informar-se e, assim, fazer certas modificações que sem a crítica ${ }^{5}$ ele nem suspeitaria da necessidade (TP, A 265) ${ }^{6}$.

Não é difícil reconhecer que Kant não poderia aceitar a teoria hobbesiana do contrato. De fato, para Kant, o contrato, como simples idéia da razão com realidade prática indubitável, "obriga todo legislador a fornecer as suas leis como se elas pudessem emanar da vontade coletiva de um povo inteiro, e a considerar todo súdito, enquanto ele quer ser cidadão, como se ele tivesse assentido pelo seu sufrágio a semelhante vontade" (TP: A 250). Portanto, diferentemente de Hobbes, em que o soberano não se vincula por nenhum pacto com os súditos, para Kant, o contrato representa o critério da legitimidade das ações do poder soberano.

\section{III}

Gostaria, agora, de passar ao ponto central desse trabalho.

Na segunda parte de TP, intitulada "Da relação da teoria à prática no direito político (contra Hobbes)", Kant defende a posição segundo a qual o povo "possui [...] os seus direitos imprescindíveis perante o chefe do Estado, embora estes não possam ser direitos de constrangimento" (TP A 264). Com base nisso, Hobbes é claramente visado por Kant. Kant faz aí referência ao capítulo VII, § 14 de Do Cidadão. Nessa passagem, Hobbes afirma:

\footnotetext{
${ }^{5}$ É claro que essa alegação de Kant não seria convincente se ela não estivesse ligada à idéia de que o Soberano deve representar a vontade geral do povo. Assim, convém ter presente que Kant defende um governo republicano. Isso significa propriamente a defesa de certo modo de governar. À republica contrapõe-se o despotismo. Enquanto na forma de governo republicana é representativa e os poderes executivo, legislativo e judiciário são atribuídos a pessoas distintas, no despotismo os poderes não estão separados e não se atende à exigência de representatividade. Na verdade, a representação envolve uma distinção entre o executor e o povo (a vontade unida desta como idéia).

${ }^{6} \mathrm{O}$ progresso em Kant, portanto, deve ser conquistado mediante reformas e não por revolução. "Por meio de uma revolução poderá talvez levar-se a cabo a queda do despotismo pessoal e da opressão gananciosa ou dominadora, mas nunca uma verdadeira reforma do modo de pensar" (Ilum.: A 484).
} 
os que detêm o poder supremo na cidade não se obrigam por nenhum pacto a ninguém. Donde se segue que os mesmos não podem cometer injúria alguma aos cidadãos (DC VII 14: 120, cf. TP A 264).

Para Kant, essa tese só poderia ter alguma validade se restringíssemos a noção de injúria à "lesão que reconhece ao lesado um direito de constrangimento" (TP II A 264)7. Mas somente no caso de injustiça implicar o reconhecimento ao lesado de um direito de constrangimento é que Kant poderia estar de acordo com Hobbes (TP A 264). Ora, Kant entende que Hobbes toma a noção de injúria, ou injustiça, na sua generalidade (TP A 264). E tomada na sua generalidade, para Kant, a tese de Hobbes se revelaria apavorante (erschrecklich) (TP A 264). O que Kant parece querer dizer é o seguinte: Hobbes defenderia que os que detêm o poder supremo tudo podem fazer, não sendo passíveis de qualquer espécie de censura aos seus atos. Portanto, Hobbes não procederia, segundo Kant, a nenhuma restrição conceitual capaz de acomodar esses conceitos à idéia de direitos inamissíveis (unverlierbaren Rechte), dentre os quais se destaca, para Kant, o direito do súdito fazer uso público da razão.

Todavia, Hobbes, ao distinguir entre injustiça e iniqüidade permite que se pense numa restrição do conceito de injúria ou injustiça. Hobbes sustenta que, embora o poder supremo não cometa injúria contra ninguém, ele pode sim cometer iniqüidade. A meu ver, Hobbes aceitaria sem nenhum problema que quem sofre injúria tem um direito de constrangimento em relação ao causador da injúria, o que não é o caso da relação soberano-súdito, mas sim da relação súdito-súdito. Ora, isso me parece simplesmente revelar um acordo entre Kant e Hobbes. Com efeito, pode-se dizer que há aí uma aproximação considerável com o segundo princípio a priori do estado civil em Kant, isto é, a igualdade.

A distinção entre injustiça e iniqüidade pode ser encontrada em L XXI $§ 7: 182^{8}$. Hobbes considera, nessa passagem, a hipótese de um príncipe levar à morte um súdito inocente. Estaria o soberano agindo contra a justiça? Segundo Hobbes, não. O soberano tem a autorização de fazer o que lhe aprouver e, assim sendo, não age injustamente. Contudo, não deixa de agir contra a lei de natureza, isto é, contra a eqüidade, pois viola um preceito moral, vale dizer, para Hobbes, um preceito divino. Hobbes pensa no caso da morte de Urias por Davi. Ele afirma:

\footnotetext{
${ }^{7}$ Kant se refere à injustiça (Unrecht), ou ao "não fazer mal" (Unrecht tun) (cf. TP II A 264). Na edição inglesa do $D C$ consta injury. Não vejo, contudo, nenhum problema na equiparação desses termos, pois para Hobbes, injúria significa a "violação de pactos" (DC VII 14, p. 120) e injustiça (injustice) igualmente não é outra coisa senão "o não cumprimento de um pacto" ( $L$ XV § 2: 86).

${ }^{8}$ Cf. também DFJ, pp. 35-36.
} 
Embora seja contrário à lei de natureza [AP: levar à morte um súdito inocente], por ser contrário à eqüidade, como foi o caso de Davi ao matar Urias, contudo não constitui dano causado a Urias, e sim a Deus. Não a Urias, porque o direito de fazer o que lhe aprouvesse lhe foi dado pelo próprio Urias, mas a Deus, porque Davi era súdito de Deus, e estava proibido de toda a iniqüidade pela lei de natureza (L XXI § 7: 182).

Com base no exposto, pode-se dizer que "são dois os termos que Hobbes usa para definir aparentemente uma mesma idéia. Injustiça (injustice) significa a violação de uma lei civil e iniqüidade (iniquity), a transgressão de uma lei natural. Daí ser compreensível Hobbes defender a idéia de que não há que se falar em injustiça no estado de natureza (cf. L XIII, § 13): antes do pacto, não há leis civis a serem violadas, mas apenas leis de natureza. $\mathrm{O}$ pacto se faz necessário, portanto, para coibir as iniqüidades do estado de natureza - ou seja, as violações das leis naturais" (Pogrebinschi 2002: 176-177).

Não é descabido afirmar - embora, provavelmente, a maioria dos leitores do Leviatã não pense assim - que, para Hobbes, o poder soberano não é absoluto. O Leviatã, Deus mortal, está submetido, como todos os seres humanos estão, às leis de natureza, isto é, às leis morais, o que vale dizer, para Hobbes, às leis divinas. Quer dizer, o Deus mortal deve se sujeitar ao Deus Imortal (cf. Pogrebinschi 2002: 167).

A crítica de Kant a Hobbes torna-se ainda mais fraca se levarmos em conta o fato de que os súditos estão livres da obrigação política para exercerem os seguintes direitos: (a) direito de resistir à morte (L XXI $\S 14$ : 186); (ii) direito de resistir a ferimentos e aprisionamentos (L XXI $§ 11$ : 185); (iii) direito de se abster do serviço militar (L XXI $\S 16$ : 186); (iv) direito de não se auto-incriminar (L XXI § 13: 185-186); (v) direito de não se obrigar pelas próprias palavras (L XXI $\S 13: 185-186$ ).

Com base no capítulo XXI do Leviatã, poder-se-ia dizer que não procede o parecer de Kant de que em Hobbes não teriam lugar direitos inamissíveis. Ora, por certo, Hobbes não concorda com Kant sobre quais são esses direitos; ele não incluiria aí "liberdade de escrever", por exemplo. Contudo, disso não segue que a sua teoria seja indiferente à idéia de que os indivíduos não renunciam a todos os seus direitos pelo contrato político. Portanto, se levarmos em conta o que Kant parece estar reclamando de Hobbes, a saber, que o povo "tem direitos imprescritíveis perante o chefe de Estado, embora estes não possam ser direitos de constrangimento" (TP: A 264), deveremos concluir que o protesto de Kant tem um alcance muito menor do que se poderia pensar à primeira vista.

Talvez valha a pena lembrar o que Kant falou sobre Hobbes nas $\mathrm{Li}$ ções de Ética. Segundo Kant, Hobbes teria defendido que a moralidade é 
instaurada pelo estado civil. Nas $L E$, ao proceder a uma classificação dos sistemas morais que se estribam em fundamentos empíricos, Kant coloca Hobbes como o representante da doutrina moral que se ampara em fundamentos externos, convencionais, do governo9. Kant entende Hobbes como um positivista moral. Com efeito, Kant sustenta que, para Hobbes,

a autoridade (die Obrigkeit) pode permitir ou proibir qualquer ação, sem dar a opção de um julgamento das ações pela razão moral, fazendo tudo depender do exemplo do costume (Beispeiel der Gewohnheit) e da ordem da autoridade, pelo que não se produziria nenhum princípio moral, exceto o derivado da experiência ( $L E$ : Ak 253/ Collins 253).

Para concluir, levanto a seguinte hipótese. Talvez se possa compreender, ainda que parcialmente, a improcedência da critica de Kant a Hobbes se levarmos em conta o fato de Kant ter se concentrado apenas no Do Cidadão, enquanto a melhor compreensão do alcance do contratualismo de Hobbes, particularmente quanto às suas conseqüências para a teoria da obrigação política, se encontra na obra Leviatã, escrita nove anos depois de Do Cidadão ${ }^{10}$. Com efeito, o capitulo XXI do Leviatã exprime vigorosamente condições de liberação da obediência política. Ora, Hobbes expõe estas condições com uma ênfase até então não colocada em suas obras anteriores, particularmente Elementos do Direito Natural e Político e Do Cidadão.

\section{Bibliografia}

BECK, Lewis White (1966): A Commentary on Kant's Critique of practical reason. Chicago: The University of Chicago Press.

BOONIN-VAIL, David (1994): Thomas Hobbes and the science of moral virtue. New York: Cambridge University Press.

HOBBES, Thomas (DC): De Cive. Elementos Filosóficos a respeito do cidadão. Tradução de Ingenberg Soler. Petrópolis: Vozes, 1993.

- (DFJ): Diálogo entre um filósofo e um jurista. Tradução de Maria Cristina Guimarães Cupertino. São Paulo: Landy, 2001.

- (EDNP): Elementos do direito natural e político. Tradução de Fernando Couto. Porto: Rés, s/d.

- (L): Leviatã, ou, Matéria, forma e poder de um estado eclesiástico e civil. Tradução de João Paulo Monteiro, Maria Beatriz Nizza da Silva e Claudia Berliner. São Paulo: Martins Fontes, 2003.

\footnotetext{
${ }^{9}$ Veja a esse respeito em Beck (1966: 104).

${ }^{10}$ A tese de que o Leviatã apresenta um desenvolvimento mais profundo que o DC e os ELNP de uma teoria da liberação da obrigação política pode ser encontrada em Pogrebinschi (2002: 191n).
} 
- (Leviathan): Leviathan. Edição J. C. A Gaskin. Oxford University Press (Oxford World's Classics), 1996.

KANT, Immanuel (Collins): "Moralphilosophie Collins". In: Vorlesungen über Moralphilosophie. Vol. IV. Kant's gesammelte Schriften. Vol. XXVII. Ed. Deutsche Akademie der. Wissenschaften. Berlin, 1974, pp. 241-473.

- (LE): Lecciones de Ética. Tradução de Roberto Rodriguez Aramayo e Concha Roldan Panadero. Barcelona. Crítica: 1988.

- (FMC): Fundamentação da Metafísica dos Costumes. Tradução de Paulo Quintela. São Paulo: Abril Cultural, 1980.

- Grundlegung zur Metaphysik der Sitten, Werkausgabe VII. Ed. W. Weischedel. Frankfurt: Suhrkamp, 1991.

- (TP): "Sobre a expressão corrente: isto pode ser correcto na teoria, mas nada vale na prática". In: À paz perpétua e outros opúsculos. Tradução de Artur Morão. Lisboa: Ed. 70, 1988, pp. 57-102.

- Über den Gemeinspruch: das mag in der Theorie richtg sein, taugt aber nicht für die Praxis. Werkausgabe VII. Ed. W. Weischedel. Frankfurt: Suhrkamp, 1991, pp. 125-172.

- (Ilum.): "Resposta à pergunta: que é o iluminismo?". In: A Paz perpétua e outros opúsculos. Tradução de Artur Morão. Lisboa: Ed. 70.

- (R): A Religião nos limites da simples razão. Tradução de Artur Morão. Lisboa: Ed. 70, 1992.

- Die Religion innerhalb der Grenzen der blossen Vernunft. Werkausgabe VIII. Ed. W. Weischedel. Frankfurt, Suhrkamp, 1991.

- (PP): À Paz perpétua. Tradução de Marco A. Zingano. Porto Alegre: L\&PM, 1989.

- (DD): Principios metafisicos de la doctrina del derecho. La Metafísica de las Costumbres. Tradução de Adela Cortina Orts e Jesus Conill Sancho. Madrid: Tecnos, 1994.

- Die Metaphysik der Sitten. Werkausgabe VIII. Ed. W. Weischedel. Frankfurt, Suhrkamp, 1991.

- (CF): O Conflito das Faculdades. Tradução de Artur Morão. Lisboa: Ed. 70, 1986.

OLIVEIRA, Nythamar Fernandes (2002): "Theoria e Praxis: Uma concepção kantiana de igualdade". Dissertatio. UFPel, 15-16, pp. 61-74.

POGREBINSCHI, Thamy (2003): O problema da obediência em Hobbes. Bauru: EDUSC.

WARRENDER, Howard (1970): The political philosophy of Hobbes - his theory of obligation. Oxford. At the Clarendon Press. 


\section{RESUMO}

Na segunda parte de TP, intitulada "Da relação da teoria à prática no direito político (contra Hobbes)", Kant faz referência ao capítulo VII, § 14 de Do Cidadão. De acordo com Kant, Hobbes somente estaria certo se reconhecesse que a injustiça implica o reconhecimento ao lesado de um direito de constrangimento. Mas Kant entende que Hobbes toma a noção de injúria, ou injustiça, na sua generalidade, quer dizer, ele não procederia, segundo Kant, a nenhuma restrição conceitual capaz de acomodar esses conceitos à idéia de direitos inamissíveis (unverlierbaren Rechte), dentre os quais se destaca, para Kant, o direito do súdito fazer uso público da razão. Todavia, Hobbes, ao distinguir entre injustiça e iniqüidade permite que se pense numa restrição do conceito de injúria ou injustiça. Hobbes sustenta que, embora o poder supremo não cometa injúria contra ninguém, ele pode sim cometer iniqüidade. A meu ver, Hobbes aceitaria sem nenhum problema que quem sofre injúria tem um direito de constrangimento em relação ao causador da injúria, o que não é o caso da relação soberano-súdito, mas sim da relação súdito-súdito. Com base nessas considerações, o artigo tem como objetivo ponderar a procedência da crítica de Kant a Hobbes em TP II. 